\title{
The rigorous determination of orthometric heights
}

Robert Tenzer ${ }^{1}$, Petr Vaníček ${ }^{1}$, Marcelo Santos ${ }^{1}$, Will E. Featherstone ${ }^{2}$, Michael Kuhn ${ }^{2}$

${ }^{1}$ Department of Geodesy and Geomatics Engineering, University of New Brunswick, P.O.

Box 4400, Fredericton, New Brunswick, E3B 5A3; Canada

${ }^{2}$ Western Australian Centre for Geodesy, Curtin University of Technology, GPO Box

U1987, Perth, WA 6845, Australia

Correspondence to: R. Tenzer (Tel.: + 1506458 7167; Fax.: + 1506453 4943; e-mail:

rtenzer@unb.ca) 
Abstract: The main problem of the rigorous definition of the orthometric height is the evaluation of the mean value of the Earth's gravity acceleration along the plumbline within the topography. To find the exact relation between rigorous orthometric and [Molodensky] normal heights, the mean gravity is decomposed into: the mean normal gravity, the mean values of gravity generated by topographical and atmospheric masses, and the mean gravity disturbance generated by the masses contained within geoid. The mean normal gravity is evaluated according to Somigliana-Pizzeti's theory of the normal gravity field generated by the ellipsoid of revolution. Using Bruns's formula, the mean values of gravity along the plumbline generated by topographical and atmospheric masses can be computed as the mean linear potential gradient between the Earth's surface and geoid. Since the gravity disturbance generated by masses inside the geoid (multiplied by the geocentric radius) is harmonic above the geoid (after removal of the topographic and atmospheric masses), its mean value along the plumbline between the Earth's surface and the geoid is obtained by solving the inverse Dirichlet boundary value problem. Numerical results for a test area in the Canadian Rocky Mountains show that the difference between the rigorously defined orthometric height and the Molodensky normal height reaches $\sim 0.5 \mathrm{~m}$.

Keywords: Mean gravity - Normal height - Orthometric height - Plumbline

\section{Introduction}

The orthometric height is the distance, measured positive outwards along the plumbline, from the geoid (zero orthometric height) to a point of interest, usually on the topographic surface (e.g., Heiskanen and Moritz 1967, chap 4; Vaníček and Krakiwsky 1986; chap 16.4). The [curved] plumbline is at every point tangential to the gravity vector generated 
by the Earth, its atmosphere and rotation. The orthometric height can be computed from the geopotential number, if available, using the mean value of the Earth's gravity acceleration along the plumbline between the geoid and Earth's surface. Alternatively and more practically, it can be computed from spirit levelling measurements using the so-called orthometric correction, embedded in which is the mean value of gravity (cf. Strang van Hees 1992). Ignoring levelling errors and the many issues surrounding practical vertical datum definition (see, e.g., Drewes at al. 2002; Lilje 1999), the rigorous determination of the orthometric height reduces to the accurate determination of the mean value of the Earth's gravity acceleration along the plumbline between the geoid and the point of interest. An appropriate method for the evaluation of the mean gravity has been discussed for more than century. The first theoretical attempt is attributed to Helmert (1890). In Helmert's definition of the orthometric height, the Poincaré-Prey gravity gradient is used to evaluate the approximate value of mean gravity from gravity observed on the Earth's surface (also see Heiskanen and Moritz 1967, chap 4; Vaníček and Krakiwsky 1986; chap 16.4). Later, Niethammer (1932) and Mader (1954) included the gravitational effect of the topography by adding the mean value of the gravimetric terrain correction within the topography. Heiskanen and Moritz (1967, p 165) also mentioned a general method for calculating mean gravity along the plumbline that includes the gravitational attraction of masses above a certain equipotential surface, thus accounting for the shape of the terrain. More recently, Vaníček et al. (unpublished), Allister and Featherstone (2001) and Hwang and Hsiao (2003) introduced further corrections due to vertical and lateral variations in the topographical mass-density. In addition to the above theoretical developments, numerous empirical studies have been published on the orthometric height (e.g., Rapp 1961; Krakiwsky 1965; Strange 1982; Kao et al. 2000; Allister and Featherstone 2001; Tenzer 
and Vaníček 2004; Hwang and Hsiao 2003; Tenzer et al. 2003; Dennis and Featherstone 2003).

Asserting that the topographical density and the actual vertical gravity gradient inside the Earth could not be determined precisely, Molodensky $(1945,1948)$ formulated the theory of normal heights. Here, the mean actual gravity within the topography is replaced by the mean normal gravity between the reference ellipsoid and the telluroid (also see Heiskanen and Moritz 1967, chap 4). Normal heights have been adopted in some countries, whereas (usually Helmert) orthometric heights have been adopted in others. An approximate formula relating normal and orthometric heights is given in Heiskanen and Moritz (1967, Eq. 8-103), with a more refined version given by Sjöberg (1995). Given that the principal difference between orthometric and normal heights is governed by the effect of physical quantities (i.e., the gravitational effects of the topography and atmosphere, and the gravity disturbance generated by the masses contained within the geoid) on the mean gravity, these are investigated in this article. It can also be argued that Molodensky's objection to the orthometric height is no longer so convincing because more and more detailed information is becoming available about the shape (i.e., digital elevation models) and mass-density distribution (e.g., from geological maps, cross-sections, boreholes and seismic surveys) inside the topography.

\section{Mean gravity along the plumbline}

Let us begin with the 'classical' definition of the orthometric height $H^{\mathrm{O}}(\Omega)$, (e.g., Heiskanen and Moritz, 1967, Eq. 4-21)

$$
\forall \Omega \in \Omega_{\mathrm{O}}: \quad H^{\mathrm{O}}(\Omega)=\frac{C\left[r_{t}(\Omega)\right]}{\bar{g}(\Omega)},
$$


where $C\left[r_{t}(\Omega)\right]$ is the geopotential number of the point of interest, which in this case will be taken on the Earth's surface $\left[r_{t}(\Omega)\right]$, and $\bar{g}(\Omega)$ is the mean value of the magnitude of gravity along the plumbline between the Earth's surface $\left(\forall \Omega \in \Omega_{0}: r_{t}(\Omega) \cong r_{g}(\Omega)+H^{\mathrm{O}}(\Omega)\right)$ and the geoid surface for which the geocentric radius is denoted by $\forall \Omega \in \Omega_{\mathrm{O}}: r_{g}(\Omega)$. To describe a 3D position, the system of geocentric coordinates $\phi, \lambda$ and $r$ is used throughout this paper, where $\phi$ and $\lambda$ are the geocentric spherical coordinates $\Omega=(\phi, \lambda), \Omega \in \Omega_{\mathrm{O}}\left(\Omega_{\mathrm{O}} \in\langle-\pi / 2 \leq \phi \leq \pi / 2 ; 0 \leq \lambda \leq 2 \pi\rangle\right)$, and $r$ denotes the geocentric radius $r \in \mathfrak{R}^{+}\left(\mathfrak{R}^{+} \in\langle 0,+\infty)\right)$.

According to the theorem of integral mean (e.g., Gradshteyn and Ryzhik 1980), the mean gravity $\bar{g}(\Omega)$ along the plumbline is defined by

$\forall \Omega \in \Omega_{\mathrm{O}}: \quad \bar{g}(\Omega)=\frac{1}{H^{\mathrm{o}}(\Omega)} \int_{r=r_{g}(\Omega)}^{r_{g}(\Omega)+H^{\mathrm{o}}(\Omega)} g(r, \Omega) \cos \left(-\mathbf{g}(r, \Omega), \mathbf{r}^{\mathbf{0}}\right) \mathrm{d} r$

where $\cos \left(-\mathbf{g}(r, \Omega), \mathbf{r}^{0}\right)$ is the cosine of the deflection of the plumbline from the geocentric radial direction, and $\mathbf{r}^{0}$ is the unit vector in the geocentric radial direction. Equation (2) is equivalent to the integral taken along the [curved] plumbline as given in Heiskanen and Moritz (1967, Eq. 4-20).

In order to analyse the mean gravity along the plumbline, the actual gravity $g(r, \Omega)$ in Eq. (2) is decomposed into the normal gravity $\gamma(r, \phi)$, the gravity disturbance generated by masses inside the geoid $\delta g^{\mathrm{NT}}(r, \Omega)$, and the gravitational attraction of topographical and atmospheric masses $g^{t}(r, \Omega)$ and $g^{a}(r, \Omega)$, respectively, so that (Tenzer et al. 2003)

$\forall \Omega \in \Omega_{\mathrm{O}}, r \in \mathfrak{R}^{+}: \quad g(r, \Omega)=\gamma(r, \phi)+\delta g^{\mathrm{NT}}(r, \Omega)+g^{t}(r, \Omega)+g^{a}(r, \Omega)$. 
Applying the above decomposition to Eq. (2), the mean gravity $\bar{g}(\Omega)$ becomes

$\forall \Omega \in \Omega_{\mathrm{O}}: \quad \bar{g}(\Omega)=\bar{\gamma}(\Omega)+\overline{\delta g}^{\mathrm{NT}}(\Omega)+\bar{g}^{t}(\Omega)+\bar{g}^{a}(\Omega)$

The relation between the mean normal gravity $\bar{\gamma}(\Omega)$ within the topography in Eq. (4) and Molodensky's mean normal gravity is formulated in Appendix A.

The main problem to be discussed in the sequel is the evaluation of the mean gravity disturbance generated by the masses inside the geoid $\overline{\delta g}^{\mathrm{NT}}(\Omega)$, and the mean topographygenerated gravitational attraction $\bar{g}^{t}(\Omega)$. The superscript NT is used here in accordance with the notation introduced in Vaníček et al. (2004) to denote a quantity reckoned in the so-called "no-topography" space, where the gravitational effect of the topographic and atmospheric masses has been removed and treated separately. The last term in Eq. (4), i.e., the mean atmosphere-generated gravitational attraction $\bar{g}^{a}(\Omega)$, is derived in Appendix B.

\section{Mean gravity disturbance generated by masses with the geoid}

The mean gravity disturbance generated by the geoid $\overline{\delta g}^{\mathrm{NT}}(\Omega)$ in Eq. (4) is given exactly by

$$
\forall \Omega \in \Omega_{\mathrm{O}}: \quad \overline{\delta g}^{\mathrm{NT}}(\Omega)=\frac{1}{H^{\mathrm{O}}(\Omega)} \int_{r=r_{g}(\Omega)}^{r_{g}(\Omega)+H^{\mathrm{O}}(\Omega)} \delta g^{\mathrm{NT}}(r, \Omega) \cos \left(-\mathbf{g}(r, \Omega), \mathbf{r}^{\mathbf{0}}\right) \mathrm{d} r
$$

In a spherical approximation $\left(\forall \Omega \in \Omega_{\mathrm{O}}: r_{g}(\Omega) \approx \mathrm{R}\right.$, where $\mathrm{R}$ is the mean radius of the Earth, see Bomford 1971), Eq. (5) reduces to

$$
\forall \Omega \in \Omega_{\mathrm{O}}: \quad \overline{\delta g}^{\mathrm{NT}}(\Omega) \cong \frac{1}{H^{\mathrm{O}}(\Omega)} \int_{r=\mathrm{R}}^{\mathrm{R}+H^{\mathrm{O}}(\Omega)} \delta g^{\mathrm{NT}}(r, \Omega) \mathrm{d} r
$$

Considering an accuracy of $<1 \mathrm{~mm}$, the spherical approximation of the geoid surface cannot be applied directly to the evaluation of the mean gravity in Eq. (2). This is 
because the Earth's gravity is at least $1.5 \times 10^{3}$ larger than the geoid-generated gravity disturbance and topography-generated gravity. Therefore, the correction to the orthometric height due to the deflection of the vertical is investigated in Appendix A. Assessing from the estimation of the maximum magnitude of the correction of mean normal gravity due to the deflection of the plumbline, the spherical approximation in Eq. (6) causes, at most, a few $\mu$ Gal error in the computation of $\overline{\delta g}^{\mathrm{NT}}(\Omega)$, which propagates as an error in the orthometric height of $<1 \mathrm{~mm}$.

In order to evaluate the geoid-generated gravity disturbance $\delta g^{\mathrm{NT}}(r, \Omega)$ on the right-hand-side of Eq. (6), Poisson's solution to the Dirichlet boundary value problem is used. This is described by the Poisson integral (e.g., Kellogg 1929)

$$
\forall \Omega \in \Omega_{\mathrm{O}}, r \geq \mathrm{R}: \quad \delta g^{\mathrm{NT}}(r, \Omega)=\frac{1}{4 \pi} \frac{\mathrm{R}}{r} \iint_{\Omega^{\prime} \in \Omega_{\mathrm{O}}} \mathrm{K}\left(r, \Omega ; \mathrm{R}, \Omega^{\prime}\right) \delta g^{\mathrm{NT}}\left[r_{g}\left(\Omega^{\prime}\right)\right] \mathrm{d} \Omega^{\prime},
$$

where $\mathrm{K}\left(r, \Omega ; \mathrm{R}, \Omega^{\prime}\right)$ is the spherical Poisson kernel, and $\delta g^{\mathrm{NT}}\left[r_{g}(\Omega)\right]$ denotes the geoidgenerated gravity disturbance specifically at the geoid surface. Inserting for $\delta g^{\mathrm{NT}}(r, \Omega)$ in Eq. (6) from Eq. (7), the mean gravity disturbance $\overline{\delta g}^{\mathrm{NT}}(\Omega)$ becomes

$$
\forall \Omega \in \Omega_{\mathrm{O}}: \overline{\delta g}{ }^{\mathrm{NT}}(\Omega) \cong \frac{1}{4 \pi} \frac{\mathrm{R}}{H^{\mathrm{O}}(\Omega)} \iint_{\Omega^{\prime} \in \Omega_{0}} \int_{r=\mathrm{R}}^{\mathrm{R}+H^{\mathrm{O}}(\Omega)} r^{-1} \mathrm{~K}\left(r, \Omega ; \mathrm{R}, \Omega^{\prime}\right) \mathrm{d} r \delta g^{\mathrm{NT}}\left[r_{g}\left(\Omega^{\prime}\right)\right] \mathrm{d} \Omega^{\prime} .
$$

The radially integrated Poisson's kernel $\overline{\mathrm{K}}\left(r, \Omega ; \mathrm{R}, \Omega^{\prime}\right)$ in Eq. (8) can be formulated as follows

$$
\begin{aligned}
\forall \Omega, \Omega^{\prime} \in \Omega_{\mathrm{O}}, r & \geq \mathrm{R}: \overline{\mathrm{K}}\left(r, \Omega ; \mathrm{R}, \Omega^{\prime}\right)=\int_{r=\mathrm{R}}^{\mathrm{R}+H^{\mathrm{O}}(\Omega)} r^{-1} \mathrm{~K}\left(r, \Omega ; \mathrm{R}, \Omega^{\prime}\right) \mathrm{d} r \\
& =\left|-2 \mathrm{R} \ell^{-1}\left(r, \Omega ; \mathrm{R}, \Omega^{\prime}\right)+\ln \right| \frac{\mathrm{R}-r \cos \psi+\ell\left(r, \Omega ; \mathrm{R}, \Omega^{\prime}\right)}{r \sin \psi}||_{r=\mathrm{R}}^{\mathrm{R}+H^{0}(\Omega)},
\end{aligned}
$$


where $\ell\left(r, \Omega ; r^{\prime}, \Omega^{\prime}\right)$ is the direct [Euclidean] distance between the computation and roving points, and the argument $\psi$ stands for the geocentric spherical distance.

To obtain the mean gravity disturbance from Eq. (8), the gravity disturbances generated by the geoid have to be first downward continued from the Earth's surface onto the geoid. Vaníček et al. (2004) define the gravity disturbances and anomalies at the Earth's surface as generated by the masses inside the geoid, as well as the evaluation of the inverse Dirichlet's boundary value problem in the (no-topography) NT-space. Alternatively, the mean value of the geoid-generated gravity disturbance $\overline{\delta g}^{\mathrm{NT}}(\Omega)$ can be obtained directly from the gravity disturbances $\delta g^{\mathrm{NT}}\left[r_{t}(\Omega)\right]$ at the Earth's surface, which, in turn, is obtained from the real gravity disturbances $\delta g\left[r_{t}(\Omega)\right]$ by subtracting the gravitational attraction of topographical and atmospheric masses from them (ibid.), i.e.,

$$
\forall \Omega \in \Omega_{\mathrm{O}}: \quad \delta g^{\mathrm{NT}}\left[r_{t}(\Omega)\right]=\delta g\left[r_{t}(\Omega)\right]-g^{t}\left[r_{t}(\Omega)\right]-g^{a}\left[r_{t}(\Omega)\right] .
$$

We shall now show how this is achieved for discrete values of the gravity disturbance.

The solution to the inverse Dirichlet's boundary value problem is described by the Poisson integral equation. To define its discretized form, the surface integration domain $\Omega \in \Omega_{\mathrm{O}}$ is split into a finite number $N$ of 'rectangular' geographical cells $\Delta \Omega_{i}=\cos \phi_{i} \Delta \phi_{i} \Delta \lambda_{i} ; i \in\langle 1,2, \ldots, N\rangle$, where $\Delta \phi$ and $\Delta \lambda$ represent steps of numerical discretization in latitude and longitude. For each geographical cell, the average value of the geoid-generated gravity disturbance $\delta g^{\mathrm{NT}}\left[r_{t}\left(\Omega_{i}\right)\right] ; i \in\langle 1,2, \ldots, N\rangle$ is evaluated at the Earth's surface. Equivalently for each corresponding geographical cell at the geoid surface, the solution of the Poisson integral equation is parameterized by discrete values of $\delta g^{\mathrm{NT}}\left[r_{g}\left(\Omega_{j}\right)\right] ; j \in\langle 1,2, \ldots, N\rangle$. 
The functional $b\left\lfloor r_{t}\left(\Omega_{i}\right) ; \mathrm{R}, \Omega_{j}\right\rfloor$ of the Poisson integral that defines the relation between $\delta g^{\mathrm{NT}}\left[r_{t}\left(\Omega_{i}\right)\right]$ and $\delta g^{\mathrm{NT}}\left[r_{g}\left(\Omega_{j}\right)\right]$ is equal to

$$
\begin{aligned}
\forall i, j \in & \langle 1,2, \ldots, N\rangle: \quad b\left[r_{t}\left(\Omega_{i}\right) ; \mathrm{R}, \Omega_{j}\right]=\frac{1}{4 \pi} \frac{\mathrm{R}}{r_{t}\left(\Omega_{i}\right)} \mathrm{K}\left[r_{t}\left(\Omega_{i}\right) ; \mathrm{R}, \Omega_{j}\right] \Delta \Omega_{j} \\
& =\frac{1}{4 \pi} \frac{\mathrm{R}^{2}}{r_{t}\left(\Omega_{i}\right)} \frac{r_{t}^{2}\left(\Omega_{i}\right)-\mathrm{R}^{2}}{\ell^{3}\left[r_{t}\left(\Omega_{i}\right) ; \mathrm{R}, \Omega_{j}\right]} \cos \phi_{j} \Delta \phi_{j} \Delta \lambda_{j} .
\end{aligned}
$$

Denoting the vector of the gravity disturbances $\delta g^{\mathrm{NT}}\left[r_{t}\left(\Omega_{i}\right)\right]$ by $\delta \mathbf{g}^{\mathrm{NT}}\left[\mathbf{r}_{\mathbf{t}}\left(\mathbf{\Omega}_{\mathbf{i}}\right)\right]$ and the vector of the gravity disturbances $\delta g^{\mathrm{NT}}\left[r_{g}\left(\Omega_{j}\right)\right]$ by $\delta \mathbf{g}^{\mathrm{NT}}\left[\mathbf{r}_{\mathbf{g}}\left(\boldsymbol{\Omega}_{\mathbf{j}}\right)\right]$, the discrete form of Poisson's integral equation is expressed by (Martinec 1996; Vaníček et al. 1996; Sun and Vaníček 1998)

$$
\left(\delta \mathbf{g}^{\mathrm{NT}}\left[\mathbf{r}_{\mathbf{g}}\left(\boldsymbol{\Omega}_{\mathbf{j}}\right)\right]\right)^{\mathrm{T}}=\mathbf{B}^{-1}\left[\mathbf{r}_{\mathbf{t}}\left(\boldsymbol{\Omega}_{\mathbf{i}}\right) ; \mathbf{R}, \boldsymbol{\Omega}_{\mathbf{j}}\right]\left(\delta \mathbf{g}^{\mathrm{NT}}\left[\mathbf{r}_{\mathbf{t}}\left(\boldsymbol{\Omega}_{\mathbf{i}}\right)\right]\right)^{\mathrm{T}},
$$

where $\mathbf{B}\left[\mathbf{r}_{\mathbf{t}}\left(\boldsymbol{\Omega}_{\mathbf{i}}\right) ; \mathbf{R}, \boldsymbol{\Omega}_{\mathbf{j}}\right\rfloor$ is the matrix of coefficients $\left.b \mid r_{t}\left(\Omega_{i}\right) ; \mathbf{R}, \Omega_{j}\right\rfloor$.

Consequently, the discrete form of the radially integrated Poisson's integral in Eq. (8) can be formulated as follows. The relation between the scalar value of the mean geoidgenerated gravity disturbance $\overline{\delta g}^{\mathrm{NT}}(\Omega)$ and the vector of the geoid-generated gravity disturbances referred to the geoid surface $\delta \mathbf{g}^{\mathrm{NT}}\left[\mathbf{r}_{\mathbf{g}}\left(\boldsymbol{\Omega}_{\mathbf{j}}\right)\right]$ is introduced by

$$
\forall \Omega \in \Omega_{\mathrm{O}}: \quad \overline{\delta g}^{\mathrm{NT}}(\Omega)=\overline{\mathbf{b}}\left[\mathbf{r}, \boldsymbol{\Omega} ; \mathbf{R}, \boldsymbol{\Omega}_{\mathbf{j}}\right]\left(\boldsymbol{\delta} \mathbf{g}^{\mathrm{NT}}\left[\mathbf{r}_{\mathbf{g}}\left(\boldsymbol{\Omega}_{\mathbf{j}}\right)\right]\right)^{\mathrm{T}},
$$

where $\overline{\mathbf{b}}\left[\mathbf{r}, \boldsymbol{\Omega} ; \mathbf{R}, \boldsymbol{\Omega}_{\mathbf{j}}\right]$ is the vector of radially integrated Poisson's kernels $\overline{\mathrm{K}}\left(r, \Omega ; \mathrm{R}, \Omega_{j}\right)$ (Eq. 9). It reads

$$
\overline{\mathbf{b}}\left[\mathbf{r}, \mathbf{\Omega} ; \mathbf{R}, \boldsymbol{\Omega}_{\mathbf{j}}\right]=\frac{1}{4 \pi} \frac{\mathrm{R}}{H^{\mathrm{O}}(\Omega)} \overline{\mathrm{K}}\left(r, \Omega ; \mathrm{R}, \Omega_{j}\right) \cos \phi_{j} \Delta \phi_{j} \Delta \lambda_{j}, j \in\langle 1,2, \ldots, N\rangle .
$$


Substituting Eq. (12) into Eq. (13), the mean gravity disturbance generated by the geoid is obtained by solving the following system of linear algebraic equations

$$
\overline{\delta g}^{\mathrm{NT}}(\Omega) \cong \overline{\mathbf{b}}\left(\mathbf{r}, \boldsymbol{\Omega} ; \mathbf{R}, \boldsymbol{\Omega}_{\mathbf{j}}\right) \mathbf{B}^{-1}\left(\mathbf{r}_{\mathbf{t}}\left(\boldsymbol{\Omega}_{\mathbf{i}}\right) ; \mathbf{R}, \boldsymbol{\Omega}_{\mathbf{j}}\right)\left(\delta \mathbf{g}^{\mathrm{NT}}\left[\mathbf{r}_{\mathbf{t}}\left(\boldsymbol{\Omega}_{\mathbf{i}}\right)\right]\right)^{\mathrm{T}},
$$

where the inequality shows that there remains only the discretization error.

A numerical experiment was conducted in our test area in the Canadian Rocky Mountains, for which digital elevation and gravity data are available. This is the same test area used for previous studies (e.g., Huang et al. 2001; Martinec 1996). For the computation of the mean geoid-generated gravity disturbances $\overline{\delta g}^{\mathrm{NT}}(\Omega)$ by solving the system of linear algebraic equations in Eq. (15), the geoid-generated gravity disturbances

$\delta g^{\mathrm{NT}}\left[r_{t}(\Omega)\right]$ at the earth surface averaged for 5' x 5' geographical grid and corresponding mean orthometric heights have been used. The number of equations has been reduced by solving Eq. (15) only for the near-zone integration sub-domain, while the far-zone contribution can be estimated from the global gravity model.

From Fig. 1, the contribution of the mean gravity disturbance generated by the geoid on the orthometric height varies between $-8 \mathrm{~cm}$ and $+44 \mathrm{~cm}$ (corresponding to heights ranging from $4 \mathrm{~m}$ to $2736 \mathrm{~m}$, and geoid-generated gravity disturbances at the earth surface ranging from $-153 \mathrm{mGal}$ to $116 \mathrm{mGal})$.

\section{Mean topography-generated gravitational attraction}

By analogy with Eq. (6), the spherical approximation of the geoid surface $\left(\forall \Omega \in \Omega_{\mathrm{O}}: r_{g}(\Omega) \approx \mathrm{R}\right)$ is assumed to evaluate the mean value of the topographygenerated gravitational attraction; this gives 
$\forall \Omega \in \Omega_{\mathrm{O}}: \quad \bar{g}^{t}(\Omega) \cong \frac{1}{H^{\mathrm{O}}(\Omega)} \int_{r=\mathrm{R}}^{\mathrm{R}+H^{\mathrm{O}}(\Omega)} g^{t}(r, \Omega) \mathrm{d} r$

Expressing the gravitational attraction $g^{t}(r, \Omega)$ as a negative radial derivative of the gravitational potential of topographical masses $V^{t}(r, \Omega)$, Eq. (16) is rewritten as

$\forall \Omega \in \Omega_{\mathrm{O}}: \quad \bar{g}^{t}(\Omega) \cong-\frac{1}{H^{\mathrm{O}}(\Omega)} \int_{r=\mathrm{R}}^{\mathrm{R}+H^{\mathrm{O}}(\Omega)} \frac{\partial V^{t}(r, \Omega)}{\partial r} \mathrm{~d} r$.

According to the Bruns formula (1878), the topography-generated gravitational attraction $\bar{g}^{t}(\Omega)$ in Eq. (17) becomes expressed as a mean linear potential gradient within the topography

$\forall \Omega \in \Omega_{\mathrm{O}}: \quad \bar{g}^{t}(\Omega) \cong \frac{V^{t}\left[r_{g}(\Omega)\right]-V^{t}\left[r_{t}(\Omega)\right]}{H^{\mathrm{O}}(\Omega)}$.

The gravitational potential of topographical masses $V^{t}(r, \Omega)$ is given by Newton's volume integral (e.g., Martinec 1998), which is evaluated at the points $r_{g}(\Omega)$ and $r_{t}(\Omega)$

$\forall \Omega \in \Omega_{\mathrm{O}}, r \in \mathfrak{R}^{+}: \quad V^{t}(r, \Omega)=\mathrm{G} \iint_{\Omega^{\prime} \in \Omega_{0}} \int_{r^{\prime}=\mathrm{R}}^{\mathrm{R}+H^{\mathrm{O}}\left(\Omega^{\prime}\right)} \rho\left(r^{\prime}, \Omega^{\prime}\right) \ell^{-1}\left(r, \Omega ; r^{\prime}, \Omega^{\prime}\right) r^{\prime 2} \mathrm{~d} r^{\prime} \mathrm{d} \Omega^{\prime}$,

where $\mathrm{G}$ denotes Newton's gravitational constant, and $\rho(r, \Omega)$ is the actual density of the topographical masses.

The Newtonian integral (Eq. 19) can be rewritten as a sum [superposition] of the contributions from the spherical Bouguer shell (cf. Wichiencharoen, 1982), 'terrain roughness' term (Martinec and Vaníček, 1994) and anomalous topographical density distribution. For the interior of topography $\Omega \in \Omega_{\mathrm{O}} \cap r \in\left\langle\mathrm{R}, \mathrm{R}+H^{\mathrm{O}}(\Omega)\right\rangle$, it reads (Wichiencharoen, 1982; see also Martinec 1998, Eq. 3.14) 


$$
\begin{aligned}
V^{t}(r, \Omega) & =2 \pi \mathrm{G} \rho_{\mathrm{o}}\left[\mathrm{R}^{2}+2 \mathrm{R} H^{\mathrm{O}}(\Omega)+\left[H^{\mathrm{O}}(\Omega)\right]^{2}-\frac{2}{3} \frac{\mathrm{R}^{3}}{r}-\frac{1}{3} r^{2}\right] \\
& +\mathrm{G} \rho_{\mathrm{o}} \iint_{\Omega^{\prime} \in \Omega_{\mathrm{O}}} \int_{r^{\prime}=\mathrm{R}+H^{\mathrm{O}}(\Omega)}^{\mathrm{R}+H^{\mathrm{O}}\left(\Omega^{\prime}\right)} \ell^{-1}\left(r, \Omega ; r^{\prime}, \Omega^{\prime}\right) r^{\prime 2} \mathrm{~d} r^{\prime} \mathrm{d} \Omega^{\prime} \\
& +\mathrm{G} \iint_{\Omega^{\prime} \in \Omega_{\mathrm{O}}} \int_{r^{\prime}=\mathrm{R}}^{\mathrm{R}+H^{\mathrm{O}}\left(\Omega^{\prime}\right)} \delta \rho\left(r^{\prime}, \Omega^{\prime}\right) \ell^{-1}\left(r, \Omega ; r^{\prime}, \Omega^{\prime}\right) r^{\prime 2} \mathrm{~d} r^{\prime} \mathrm{d} \Omega^{\prime},
\end{aligned}
$$

where the topographical density $\rho(r, \Omega)$ is divided between the mean topographical density $\rho_{\mathrm{o}}$ and anomalous topographical density $\delta \rho(r, \Omega)$, such that $\rho(r, \Omega)=\rho_{\mathrm{o}}+\delta \rho(r, \Omega)$.

Substitution of Eq. (20) into Eq. (18) yields

$$
\begin{aligned}
\forall \Omega \in \Omega_{\mathrm{O}}: \bar{g}^{t}(\Omega) \cong 2 \pi \mathrm{G} \rho_{\mathrm{o}} H^{\mathrm{O}}(\Omega)\left[1+\frac{2}{3} \frac{H^{\mathrm{O}}(\Omega)}{\mathrm{R}}\right] \\
\quad+\frac{\mathrm{G} \rho_{\mathrm{o}}}{H^{\mathrm{O}}(\Omega)} \iint_{\Omega^{\prime} \in \Omega_{\mathrm{O}}} \int_{r^{\prime}=\mathrm{R}+H^{\mathrm{O}}(\Omega)}^{\mathrm{R}+H^{\mathrm{O}}\left(\Omega^{\prime}\right)}\left(\ell^{-1}\left(\mathrm{R}, \Omega ; r^{\prime}, \Omega^{\prime}\right)-\ell^{-1}\left[r_{t}(\Omega) ; r^{\prime}, \Omega^{\prime}\right]\right) r^{\prime 2} \mathrm{~d} r^{\prime} \mathrm{d} \Omega^{\prime} \\
+\frac{\mathrm{G}}{H^{\mathrm{O}}(\Omega)} \iint_{\Omega^{\prime} \in \Omega_{\mathrm{O}}} \int_{r^{\prime}=\mathrm{R}}^{\mathrm{R}+H^{\mathrm{O}}\left(\Omega^{\prime}\right)} \delta \rho\left(r^{\prime}, \Omega^{\prime}\right)\left(\ell^{-1}\left(\mathrm{R}, \Omega ; r^{\prime}, \Omega^{\prime}\right)-\ell^{-1}\left[r_{t}(\Omega) ; r^{\prime}, \Omega^{\prime}\right]\right) r^{\prime 2} \mathrm{~d} r^{\prime} \mathrm{d} \Omega^{\prime} .
\end{aligned}
$$

Treating the spherical Bouguer shell and terrain roughness terms separately, computations were performed in the same test area of the Canadian Rocky Mountains (cf. Fig. 1). The mean values of the gravitational attraction generated by the spherical Bouguer term have been computed simply according to the first term in Eq. (21), while for computation of the mean spherical terrain corrections the detailed 3" x 3" digital terrain model has been used for the numerical integration up to 3 degree of the spherical distance $\psi$ around the computation point. Since the reciprocal spatial distances $\ell^{-1}\left(\mathrm{R}, \Omega ; r^{\prime}, \Omega^{\prime}\right)$ and $\ell^{-1}\left[r_{t}(\Omega) ; r^{\prime}, \Omega^{\prime}\right]$ are practically equal for $\psi>3^{\circ}$, the far-zone contribution in the second term on the right-hand-side of Eq. (21) is negligible. The effect of the spherical Bouguer 
shell on the orthometric height $H^{\mathrm{O}}(\Omega)$, given by the first term on the right-hand-side of Eq. (21), ranges from $0 \mathrm{~cm}$ to $-74.4 \mathrm{~cm}$ (Fig. 2). Likewise, the effect of terrain roughness term on the orthometric height $H^{\mathrm{O}}(\Omega)$ ranges between $-10 \mathrm{~cm}$ and $+6 \mathrm{~cm}$ (Fig. 3). These values assume a constant topographical mass-density.

Disregarding water bodies, the variation of actual topographical mass density is mostly within $\pm 300 \mathrm{~kg} \cdot \mathrm{m}^{-3}$ of the mean value $\rho_{\mathrm{o}}=2670 \mathrm{~kg} \cdot \mathrm{m}^{-3}$. Therefore, the influence of anomalous topographical density $\delta \rho(r, \Omega)$ amounts to $\sim 10 \%$ of the total effect of topographical masses (Huang et al. 2001). However, larger topographical mass density variations (20-30\%) are encountered in some other parts of the world (e.g., Tziavos and Featherstone 2000). Therefore, mass density variations generate $\mathrm{cm}$ to $\mathrm{dm}$ effects on the orthometric height (Vaníček et al. 1995; Tenzer et al., 2003; Tenzer and Vaníček, 2004; cf. Hwang and Hsiao 2003; Allister and Featherstone 2001). In the test area used here, this effect ranges from -7 to $+2 \mathrm{~cm}$ (Fig. 4), where the topographical mass density data are the same as those used by Huang et al. (2001). Finally, the total effect of topography on the orthometric height, as described by Eq. (21), varies between $+0.1 \mathrm{~cm}$ and $-86.5 \mathrm{~cm}$ in the test area (Fig. 5).

\section{Discussion and conclusions}

The definition of mean gravity along the plumbline in Eq. (4), which is essential to rigorously compute the orthometric height, can be considered to consist of two parts. The first part, independent of the actual gravity field, represents the mean normal gravity (Appendix A), while the second part defines the mean value of the actual gravity disturbance between the geoid and Earth's topography surface. According to Eq. (4), this 
mean gravity disturbance is further decomposed into the mean gravity disturbance generated by the geoid (Section 3) and the mean values of the gravitational attraction of topographical masses, comprising the Bouguer shell, terrain roughness and lateral density variations (Section 4), and the [smaller-valued] atmospheric masses (Appendix B).

It follows from the theoretical investigation in Appendix A that the mean normal gravity between the Earth's surface and the geoid is defined in terms of Molodensky's mean normal gravity between the telluroid and the ellipsoid surface, plus the reductions of mean normal gravity due to the deflection and curvature of the plumbline, the height anomaly and the geoid-to-quasigeoid separation. Considering now their global effects: The correction of mean normal gravity due to the height anomaly is introduced in Eq. (A12). For the maximum value of the height anomaly $\mp 100.0 \mathrm{~m}$, this correction reaches $\pm 31 \mathrm{mGal}$, which in turn corresponds to an influence on the orthometric height of up to 25 cm. Considering that the maximum vertical displacement between the geoid and quasigeoid is $\sim 2 \mathrm{~m}$ (e.g., Sjöberg 1995), the geoid-to-quasigeoid correction to the mean normal gravity can reach up to $0.3 \mathrm{mGal}$. Based on Eq. (A14), the maximum magnitude of the correction of mean normal gravity due to the deflection of the plumbline is estimated to be $\sim 2.1 \mathrm{mGal}$ for an [extreme] 2-arc-minute deflection. Hence, the geoid-to-quasigeoid correction to the mean normal gravity and the correction of mean normal gravity due to the deflection of the plumbline cause, at most, a few mm change in the orthometric height.

From the numerical investigations conducted in a high-elevation and rugged part of the Canadian Rocky Mountains (Sections 3 and 4), the effect of topography and the effect due to the gravity disturbance generated by the masses inside the geoid cause up to several $\mathrm{dm}$ of change in the orthometric height. The total influence of these two effects on the 
orthometric height, which is identical to the difference between the rigorous orthometric height defined here and Molodensky normal height, varies from $-0.1 \mathrm{~cm}$ to $-45.6 \mathrm{~cm}$ (Fig. 6). The absence of positive difference values in this test area is because the dominant part of the influence is caused by the spherical Bouguer term (Fig. 2). On the other hand, from Appendix B and Tenzer et al. (2004), the mean atmosphere-generated gravitational attraction varies between $-0.01 \mathrm{mGal}$ and $-0.10 \mathrm{mGal}$ and thus has a negligible influence $(<<1 \mathrm{~mm})$ on the orthometric height.

Acknowledgements. The research described here was conducted under auspices of the "GEOIDE Network of Centres of Excellence" in Canada and Australian Research Council grant DP0211827. The data used were kindly supplied by the Geodetic Survey Division of Natural Resources Canada. We would also like to thank the reviewers for their constructive comments.

\section{References}

Allister NA, Featherstone WE (2001) Estimation of Helmert orthometric heights using digital barcode levelling, observed gravity and topographic mass-density data over part of Darling Scarp, Western Australia. Geom Res Aust 75: 25-52

Bomford G (1971) Geodesy ( $3^{\text {rd }}$ edn). Oxford University Press, Oxford

Bruns H (1878) Die Figur der Erde. Publ. Preuss. Geod. Inst., Berlin

Dennis ML, Featherstone WE (2003) Evaluation of orthometric and related height systems using a simulated mountain gravity field. in: Tziavos IN (ed) Gravity and Geoid 2002, Dept Surv \& Geod, Aristotle Univ Thessaloniki, pp 389-394 
Drewes H, Dodson AH, Fortes LP, Sanchez L, Sandoval P (Eds.) (2002) Vertical Reference Systems. IAG Symposia 24, Springer, Berlin, 353 pp

Gradshteyn IS, Ryzhik IM (1980) Table of Integrals, Series and Products (corrected \& enlarged end), translated by A. Jeffrey, Academic Press, New York

Heiskanen WH, Moritz H (1967) Physical geodesy. WH Freeman and Co., San Francisco

Helmert FR (1890) Die Schwerkraft im Hochgebirge, insbesondere in den Tyroler Alpen. Veröff. Königl. Preuss. Geod. Inst., No. 1

Huang J, Vaníček P, Pagiatakis SD, Brink W (2001) Effect of topographical density on the geoid in the Rocky Mountains. J Geod 74: 805-815

Hwang C, Hsiao YS (2003) Orthometric height corrections from leveling, gravity, density and elevation data: a case study in Taiwan. J Geod 77(5-6): 292-302

Kao SP, Rongshin H, Ning FS (2000) Results of field test for computing orthometric correction based on measured gravity. Geom Res Aus 72: 43-60

Kellogg OD (1929) Foundations of potential theory. Springer, Berlin

Krakiwsky EJ (1965) Heights, M.S. Thesis, Dept Geod Sci \& Surv, Ohio State Univ, Columbus, $157 \mathrm{pp}$

Lilje M (Ed.) (1999) Geodesy and Surveying in the Future - The Importance of Heights, LMV Rep. 1999:3, National Land Survey, Gävle, Sweden, 418 pp

MacMillan WD (1930) The theory of the potential. Dover, New York

Mader K (1954) Die orthometrische Schwerekorrektion des Präzisions-Nivellements in den Hohen Tauern. Österreichische Zeitschrift für Vermessungswesen, Sonderheft 15

Martinec Z, Vaníček P (1994) Direct topographical effect of Helmert's condensation for a spherical approximation of the geoid. Manusc Geod 19: 257-268. 
Martinec Z (1996) Stability investigations of a discrete downward continuation problem for geoid determination in the Canadian Rocky Mountains. J Geod 70: 805-828

Martinec Z (1998) Boundary value problems for gravimetric determination of a precise geoid. Lecture notes in Earth Sciences, Vol. 73, Springer, Berlin

Molodensky MS (1945) Fundamental Problems of Geodetic Gravimetry (in Russian). TRUDY Ts NIIGAIK Vol. 42, Geodezizdat, Moscow

Molodensky MS (1948) External gravity field and the shape of the Earth surface (in Russian). Izv. CCCP, Moscow

Molodensky MS, Yeremeev VF, Yurkina MI (1960) Methods for Study of the External Gravitational Field and Figure of the Earth. TRUDY Ts NIIGAiK, Vol. 131, Geodezizdat, Moscow. English translation: Israel Program for Scientific Translation, Jerusalem 1962

Niethammer T (1932) Nivellement und Schwere als Mittel zur Berechnung wahrer Meereshöhen. Schweizerische Geodätische Kommission

Novák P (2000) Evaluation of gravity data for the Stokes-Helmert solution to the geodetic boundary-value problem. Tech Rep 207, Dept Geodesy \& Geomatics Eng, Univ New Brunswick, Fredericton

Rapp RH (1961) The orthometric height, M.S. Thesis, Dept Geodc Sci, Ohio State Univ, Columbus, USA, $117 \mathrm{pp}$

Sjöberg LE (1995) On the quasigeoid to geoid separation. manuscr geod 20(3): 182-192

Sjöberg LE (1999) The IAG approach to the atmospheric geoid correction in Stokes's formula and a new strategy. J Geod 73 (7): 362-366

Sjöberg LE (2001) Topographic and atmospheric corrections of the gravimetric geoid determination with special emphasis of the effects of degrees zero and one. J Geod 
75: $283-290$

Strange WE (1982) An evaluation of orthometric height accuracy using borehole gravimetry. Bull Géod 56: 300-311

Sun W, Vaníček P (1998) On some problems of the downward continuation of the 5'x 5' mean Helmert gravity disturbance. J Geod 72: 411-420

Sünkel H (1986) Digital height and density model and its use for the orthometric height and gravity field determination for Austria, Proc Int Symp on the Definition of the Geoid, Florence, Italy, May, pp 599-604

Tenzer R, Vaníček P (2004) Correction to Helmert's orthometric height due to actual lateral variation of topographical density. Brazilian Journal of Cartography - Revista Brasileira de Cartografia, Brasil (submitted)

Tenzer R, Vaníček P, Santos M (2003) Corrections to Helmert's Orthometric Heights. Proceedings of IUGG symposia, Sapporo

Tenzer R, Vaníček P, Santos M (2004) Mean gravity along the plumbline. CGU and AGU Annual Scientific Meeting, Montreal, May 17-21, 2004, Canada

Tziavos IN, Featherstone WE (2001) First results of using digital density data in gravimetric geoid computation in Australia, in: Sideris MG (ed) Gravity, Geoid and Geodynamics 2000, Springer, Berlin, pp 335-340

Vaníček P, Huang J, Novák P, Pagiatakis SD, Véronneau M, Martinec Z, Featherstone WE (1999) Determination of the boundary values for the Stokes-Helmert problem. J Geodesy 73: 180 - 192

Vaníček P, Kleusberg A, Martinec Z, Sun W, Ong P, Najafi M, Vajda P, Harrie L, Tomášek P, Horst B (1995) Compilation of a precise regional geoid. Final report on research done for the Geodetic Survey Division, Fredericton 
Vaníček P, Krakiwsky E (1986) Geodesy the concepts (2nd edn). Elsevier, Amsterdam

Vaníček P, Sun W, Ong P, Martinec Z, Najafi M, Vajda P, Horst B (1996) Downward continuation of Helmert's gravity. J Geod 71: 21-34

Vaníček P, Tenzer R, Sjöberg LE, Martinec Z, Featherstone WE (submitted) New views of the spherical Bouguer gravity anomaly. Geophys J Int (submitted Aug 2003)

Wichiencharoen C (1982) The indirect effects on the computation of geoid undulations. Dept of Geod Sci Report, No. 336, Ohio State University 


\section{Appendix A: Mean normal gravity within the topography}

The mean normal gravity $\bar{\gamma}(\Omega)$ in Eq. (4) reads

$\forall \Omega \in \Omega_{\mathrm{O}}: \quad \bar{\gamma}(\Omega)=\frac{1}{H^{\mathrm{O}}(\Omega)} \int_{r=r_{g}(\Omega)}^{r_{g}(\Omega)+H^{\mathrm{O}}(\Omega)} \gamma(r, \phi) \cos \theta(r, \Omega) \cos \left(-\mathbf{g}(r, \Omega), \mathbf{r}^{\mathbf{0}}\right) \mathrm{d} r$,

where $\cos \theta(r, \Omega)$ reduces the normal gravity along the ellipsoidal normal to the plumbline.

The deflection of the plumbline from the geocentric radial direction is given by (Vaníček et al. 1999)

$\forall \Omega \in \Omega_{\mathrm{O}}, r \in \mathfrak{R}^{+}: \quad \cos \left(-\mathbf{g}(r, \Omega), \mathbf{r}^{\mathbf{0}}\right) \approx 1-\frac{(\mathrm{f} \sin 2 \varphi+\xi(r, \Omega))^{2}}{2}-\frac{\eta^{2}(r, \Omega)}{2}$,

where $\varphi$ denotes the geodetic latitude, $\mathrm{f}$ is the first numerical flattening of the geocentric reference ellipsoid, and $\xi(r, \Omega)$ and $\eta(r, \Omega)$ are, respectively, the meridian and prime vertical components of the deflection of the vertical $\theta(r, \Omega) ; \forall \Omega \in \Omega_{\mathrm{O}}, r \in \mathfrak{R}^{+}$: $\theta^{2}(r, \Omega)=\xi^{2}(r, \Omega)+\eta^{2}(r, \Omega)$

The cosine of the deflection of the plumbline $\theta(r, \Omega)$ can be expressed by (Vaníček and Krakiwsky 1986)

$\forall \Omega \in \Omega_{\mathrm{O}}, r \in \mathfrak{R}^{+}: \quad \cos \theta(r, \Omega) \approx 1-\frac{\theta^{2}(r, \Omega)}{2}=1-\frac{\xi^{2}(r, \Omega)}{2}-\frac{\eta^{2}(r, \Omega)}{2}$.

Multiplying Eqs. (A2) and (A3) gives the following relation $\forall \Omega \in \Omega_{\mathrm{O}}, r \in \mathfrak{R}^{+}:$

$$
\cos \theta(r, \Omega) \cos \left(-\mathbf{g}(r, \Omega), \mathbf{r}^{\mathbf{0}}\right) \approx 1-\xi(r, \Omega) \mathrm{f} \sin 2 \varphi-\theta^{2}(r, \Omega)-\frac{\mathrm{f}^{2} \sin ^{2} 2 \varphi}{2}
$$

Considering Eq. (A4), the mean normal gravity $\bar{\gamma}(\Omega)$ in Eq. (A1) is rewritten as 
$\forall \Omega \in \Omega_{0}:$

$\bar{\gamma}(\Omega) \cong \frac{1}{H^{\mathrm{O}}(\Omega)} \int_{r=r_{g}(\Omega)}^{r_{g}(\Omega)+H^{\mathrm{O}}(\Omega)} \gamma(r, \phi)\left(1-\xi(r, \Omega) \mathrm{f} \sin 2 \varphi-\theta^{2}(r, \Omega)-\frac{\mathrm{f}^{2} \sin ^{2} 2 \varphi}{2}\right) \mathrm{d} r$.

Molodensky's (1945 and 1960) mean normal gravity $\bar{\gamma}^{\mathrm{N}}(\Omega)$ between the telluroid $\forall \Omega \in \Omega_{\mathrm{O}}: r_{o}(\phi)+H^{\mathrm{N}}(\Omega)$ and the surface of the geocentric reference ellipsoid $\forall \phi \in\langle-\pi / 2, \pi / 2\rangle: r_{o}(\phi)$ reads

$\forall \Omega \in \Omega_{\mathrm{O}}: \quad \bar{\gamma}^{\mathrm{N}}(\Omega)=\frac{1}{H^{\mathrm{N}}(\Omega)} \int_{r=r_{o}(\phi)}^{r_{o}(\phi)+H^{\mathrm{N}}(\Omega)} \gamma(r, \phi) \cos \left(-\gamma(r, \phi), \mathbf{r}^{\mathrm{o}}\right) \mathrm{d} r$,

where $\gamma(r, \phi)$ is the vector of normal gravity, and $H^{\mathrm{N}}(\Omega)$ is the [Molodensky] normal height. Using the relation between geocentric and geodetic latitudes (Bomford 1971), i.e., $\forall \phi \in\langle-\pi / 2, \pi / 2\rangle: \quad \cos \left(-\gamma(r, \phi), \mathbf{r}^{0}\right)=\cos (\mathrm{f} \sin 2 \varphi) \approx 1-\frac{1}{2} \mathrm{f}^{2} \sin ^{2} 2 \varphi$,

Equation (A6) further takes the form

$\forall \Omega \in \Omega_{\mathrm{O}}: \quad \bar{\gamma}^{\mathrm{N}}(\Omega)=\frac{1}{H^{\mathrm{N}}(\Omega)} \int_{r=r_{o}(\phi)}^{r_{o}(\phi)+H^{\mathrm{N}}(\Omega)} \gamma(r, \phi)\left(1-\frac{1}{2} \mathrm{f}^{2} \sin ^{2} 2 \varphi\right) \mathrm{d} r$.

The first term on the right-hand-side of Eq. (A5), i.e., the mean normal gravity along the radial direction, can be defined as the mean linear gradient of the normal gravity potential between the geoid and the Earth's surface

$$
\forall \Omega \in \Omega_{\mathrm{O}}: \quad \bar{\gamma}(\Omega) \cong \frac{1}{H^{\mathrm{O}}(\Omega)} \int_{r=r_{g}(\Omega)}^{r_{g}(\Omega)+H^{\mathrm{O}}(\Omega)} \gamma(r, \phi) \mathrm{d} r=\frac{U\left\lfloor r_{g}(\Omega)\right]-U\left[r_{t}(\Omega)\right]}{H^{\mathrm{O}}(\Omega)} .
$$

By analogy with Eq. (A9), the first term of Molodensky's mean normal gravity in Eq. (A8) is defined as the mean linear gradient of the normal gravity potential between the ellipsoid surface and the telluroid, so that 
$\forall \Omega \in \Omega_{\mathrm{O}}:$

$$
\bar{\gamma}^{\mathrm{N}}(\Omega) \cong \frac{1}{H^{\mathrm{N}}(\Omega)} \int_{r=r_{o}(\phi)}^{r_{o}(\phi)+H^{\mathrm{N}}(\Omega)} \gamma(r, \phi) \mathrm{d} r=\frac{U\left[r_{o}(\phi)\right]-U\left[r_{o}(\phi)+H^{\mathrm{N}}(\Omega)\right]}{H^{\mathrm{N}}(\Omega)} .
$$

Comparing Eqns. (A9) and (A10), the following relation is obtained

$\forall \Omega \in \Omega_{\mathrm{O}}:$

$$
\bar{\gamma}(\Omega)-\left.\bar{\gamma}^{\mathrm{N}}(\Omega) \cong \frac{\partial \gamma(r, \phi)}{\partial \mathrm{n}}\right|_{r=r_{o}(\phi)} \varsigma(\Omega)-\left.\frac{1}{2} \frac{\partial \gamma(r, \phi)}{\partial \mathrm{n}}\right|_{r=r_{o}(\phi)}\left(H^{\mathrm{O}}(\Omega)-H^{\mathrm{N}}(\Omega)\right),
$$

where $\varsigma(\Omega)$ is the height anomaly.

It therefore follows from Eq. (A11) that two corrections are needed to reduce Molodensky's mean normal gravity $\bar{\gamma}^{\mathrm{N}}(\Omega)$ to the mean normal gravity $\bar{\gamma}(\Omega)$ between the geoid and the Earth's surface: one due to the height anomaly, and another due to the geoidto-quasigeoid separation.

1. The correction of mean normal gravity due to the height anomaly $\varepsilon_{\bar{\gamma}}^{\varsigma}(\Omega)$ represents the shift of the integration interval from the telluroid to the Earth's surface

$$
\forall \Omega \in \Omega_{\mathrm{O}}:\left.\quad \varepsilon_{\bar{\gamma}}^{\varsigma}(\Omega) \cong \frac{\partial \gamma(r, \phi)}{\partial \mathrm{n}}\right|_{r=r_{o}(\phi)} \varsigma(\Omega) \approx-\frac{2 \gamma_{o}(\phi)}{\mathrm{a}} \varsigma(\Omega),
$$

where $\gamma_{o}(\phi)$ is the normal gravity on the ellipsoid surface.

2. The geoid-to-quasigeoid correction to the mean normal gravity $\varepsilon_{\bar{\gamma}}^{H}(\Omega)$ caused by a different length of the integration intervals is given by

$$
\begin{aligned}
& \forall \Omega \in \Omega_{\mathrm{O}}: \\
& \varepsilon_{\bar{\gamma}}^{H}(\Omega) \cong-\left.\frac{1}{2} \frac{\partial \gamma(r, \phi)}{\partial \mathrm{n}}\right|_{r=r_{o}(\phi)}\left(H^{\mathrm{O}}(\Omega)-H^{\mathrm{N}}(\Omega)\right) \approx \frac{\gamma_{o}(\phi)}{\mathrm{a}}\left(H^{\mathrm{O}}(\Omega)-H^{\mathrm{N}}(\Omega)\right) .
\end{aligned}
$$


Comparing the second-order terms in Eqs. (A5) and (A8), the correction of mean normal gravity due to the deflection of the plumbline $\varepsilon_{\bar{\gamma}}^{\theta}(\Omega)$ is introduced finally as

$\forall \Omega \in \Omega_{\mathrm{O}}: \quad \varepsilon_{\bar{\gamma}}^{\theta}(\Omega) \cong-\frac{1}{H^{\mathrm{O}}(\Omega)} \int_{r=r_{g}(\Omega)}^{r_{g}(\Omega)+H^{\mathrm{O}}(\Omega)} \gamma(r, \phi)\left(\xi(r, \Omega) \mathrm{f} \sin 2 \varphi+\theta^{2}(r, \Omega)\right) \mathrm{d} r . \quad(\mathrm{A} 14)$ 


\section{Appendix B: Mean atmosphere-generated gravitational attraction}

By analogy with Eq. (18), the mean value of the atmosphere-generated gravitational attraction $\bar{g}^{a}(\Omega)$ in Eq. (4) reads

$\forall \Omega \in \Omega_{\mathrm{O}}: \quad \bar{g}^{a}(\Omega) \cong \frac{1}{H^{\mathrm{O}}(\Omega)} \int_{r=\mathrm{R}}^{\mathrm{R}+H^{\mathrm{O}}(\Omega)} g^{a}(r, \Omega) \mathrm{d} r=\frac{V^{a}\left[r_{g}(\Omega)\right]-V^{a}\left[r_{t}(\Omega)\right]}{H^{\mathrm{O}}(\Omega)}$,

where $V^{a}(r, \Omega)$ is the gravitational potential of the atmospheric masses.

Considering only the radially distributed atmospheric mass-density $\rho^{a}(r)$, the gravitational potential $V^{a}(r, \Omega)$ of atmospheric masses is given by (Sjöberg 1999, 2001; Novák 2000)

$$
\begin{aligned}
\forall \Omega \in \Omega_{\mathrm{O}}, r \in \Re^{+}: \quad V^{a}(r, \Omega) \cong \mathrm{G} \iint_{\Omega^{\prime} \in \Omega_{\mathrm{O}}} \int_{r^{\prime}=\mathrm{R}+H^{\mathrm{o}}\left(\Omega^{\prime}\right)}^{\mathrm{R}+\mathrm{H}_{\max }} \rho^{a}\left(r^{\prime}\right) \ell^{-1}\left(r, \Omega ; r^{\prime}, \Omega^{\prime}\right) r^{\prime 2} \mathrm{~d} r^{\prime} \mathrm{d} \Omega^{\prime} \\
+\mathrm{G} \iint_{\Omega^{\prime} \in \Omega_{\mathrm{O}}} \int_{r^{\prime}=\mathrm{R}+\mathrm{H}_{\max }}^{\mathrm{r}_{\mathrm{im}}} \rho^{a}\left(r^{\prime}\right) \ell^{-1}\left(r, \Omega ; r^{\prime}, \Omega^{\prime}\right) r^{\prime 2} \mathrm{~d} r^{\prime} \mathrm{d} \Omega^{\prime}
\end{aligned}
$$

The volume integration domain within the Earth's atmosphere in Eq. (B2) is divided into an 'atmospheric spherical Bouguer shell' and an 'atmospheric roughness term' (analogously with the treatment of the topographic masses). The atmospheric spherical shell is defined between the upper limit of the topography $\forall \Omega \in \Omega_{\mathrm{O}}: \mathrm{r}=\mathrm{R}+\mathrm{H}_{\max }$ $\left(\forall \Omega \in \Omega_{\mathrm{O}}: \mathrm{H}_{\max }=\max H^{\mathrm{o}}(\Omega)\right)$ and the upper limit of the atmosphere $\forall \Omega \in \Omega_{\mathrm{O}}: \mathrm{r}=\mathrm{r}_{\text {lim }}$. The atmospheric roughness term is enclosed by the Earth's surface and the upper limit of topography. Essentially, this is a mirror of the complete spherical Bouguer correction, but applies to the atmosphere and is consequently a smaller-valued term. 
Since the gravitational potential of atmospheric spherical shell (given by the second integral on the right-hand side of Eq. B2) is constant in the interior $\Omega \in \Omega_{\mathrm{O}} \cap r<\mathrm{R}+\mathrm{H}_{\max }$ (e.g., MacMillan 1930)

$$
\mathrm{G} \iint_{\Omega^{\prime} \in \Omega_{0}} \int_{r^{\prime}=\mathrm{R}+\mathrm{H}_{\max }}^{\mathrm{r}_{\mathrm{lim}}} \rho^{a}\left(r^{\prime}\right) \ell^{-1}\left(r, \Omega ; r^{\prime}, \Omega^{\prime}\right) r^{\prime 2} \mathrm{~d} r^{\prime} \mathrm{d} \Omega^{\prime}=4 \pi \mathrm{G} \int_{r^{\prime}=\mathrm{R}+\mathrm{H}_{\max }}^{\mathrm{r}_{\mathrm{lim}}} \rho^{a}\left(r^{\prime}\right) r^{\prime} \mathrm{d} r^{\prime}
$$

the mean value $\bar{g}^{a}(\Omega)$ of the atmosphere-generated gravitational attraction in Eq. (B1) reduces to

$$
\forall \Omega \in \Omega_{\mathrm{O}}:
$$

$$
\bar{g}^{a}(\Omega) \cong \frac{\mathrm{G}}{H^{\mathrm{O}}(\Omega)} \iint_{\Omega^{\prime} \in \Omega_{\mathrm{O}}} \int_{r^{\prime}=\mathrm{R}+H^{\mathrm{O}}\left(\Omega^{\prime}\right)}^{\mathrm{R}+\mathrm{H}_{\max }} \rho^{a}\left(r^{\prime}\right)\left(\ell^{-1}\left(\mathrm{R}, \Omega ; r^{\prime}, \Omega^{\prime}\right)-\ell^{-1}\left[r_{t}(\Omega) ; r^{\prime}, \Omega^{\prime}\right]\right) r^{\prime 2} \mathrm{~d} r^{\prime} \mathrm{d} \Omega^{\prime}
$$




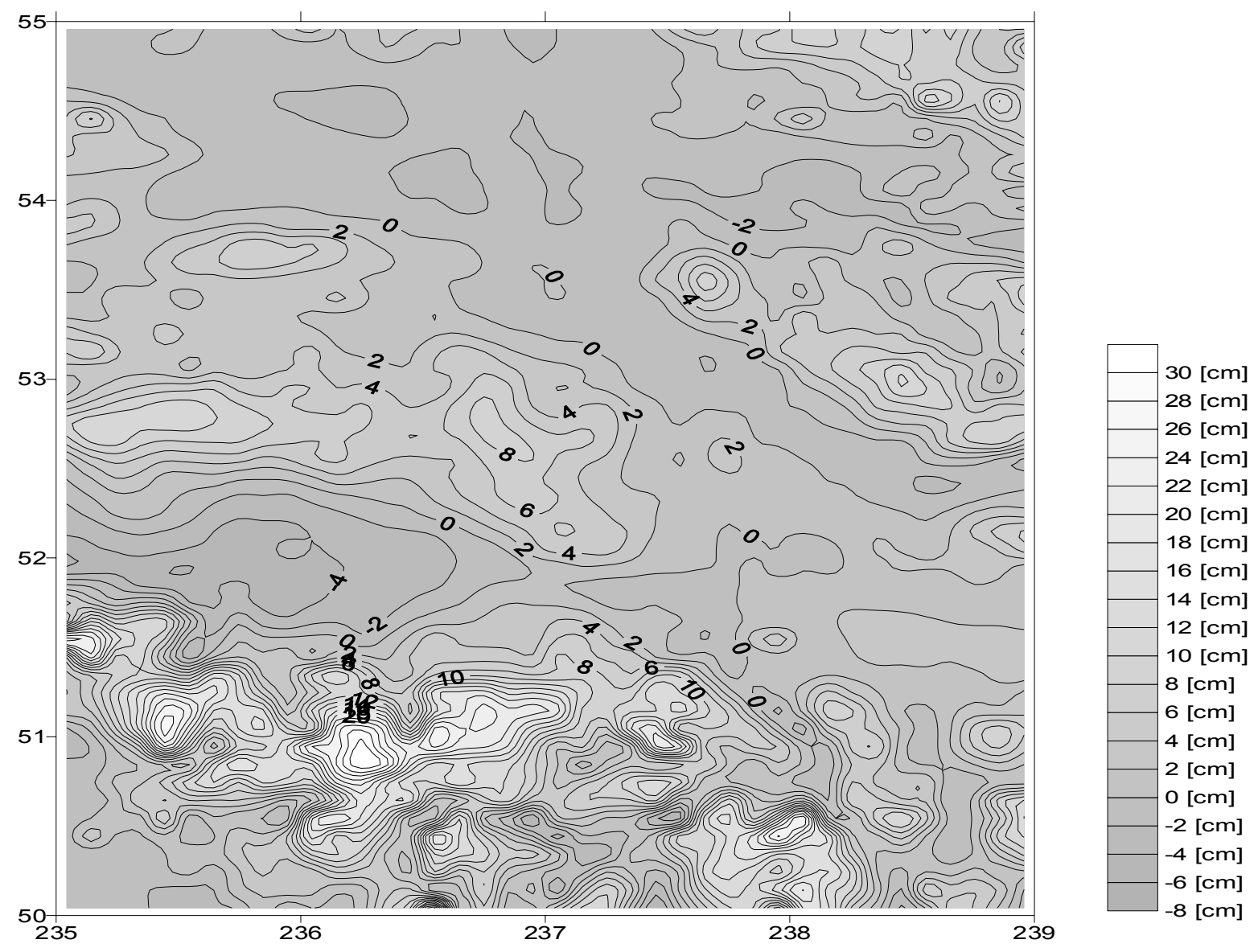

Figure 1. Effect of the mean gravity disturbance generated by masses inside the geoid on the orthometric height (units in $\mathrm{cm}$ ) 


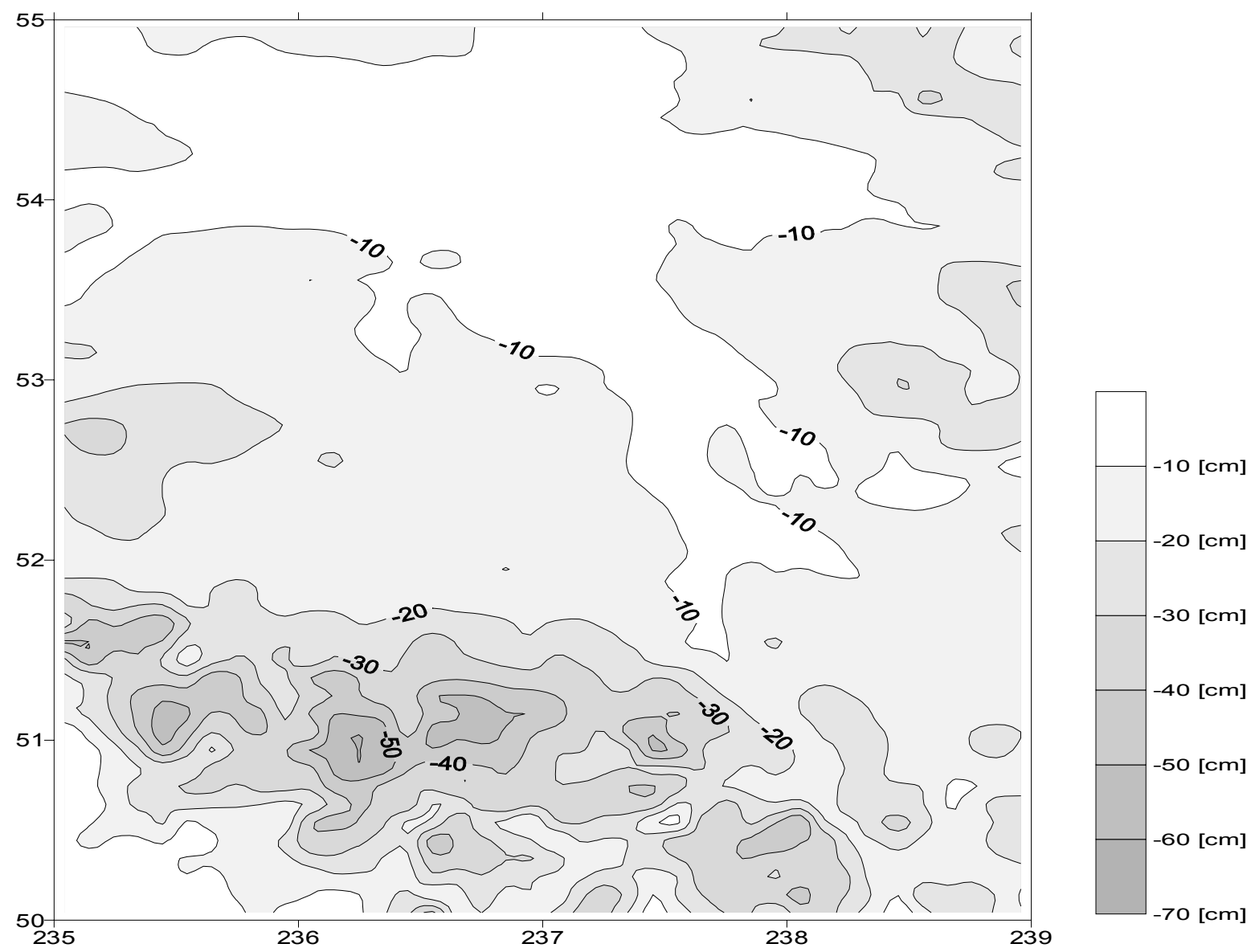

Figure 2. Effect of the spherical Bouguer shell's gravitation on the orthometric height (units in $\mathrm{cm}$ ) 


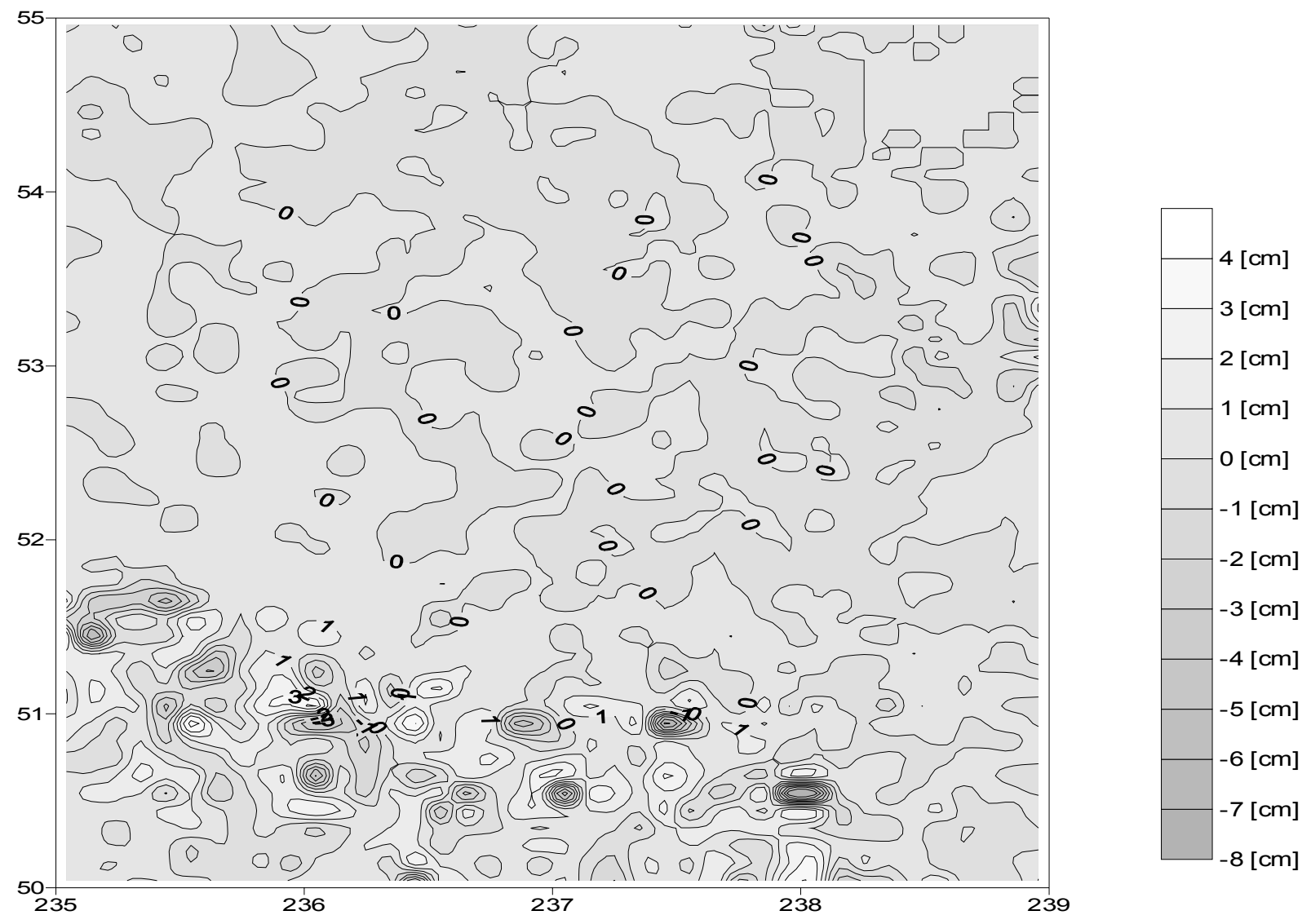

Figure 3. Effect of terrain roughness term's gravitation on the orthometric height (unis in $\mathrm{cm}$ ) 


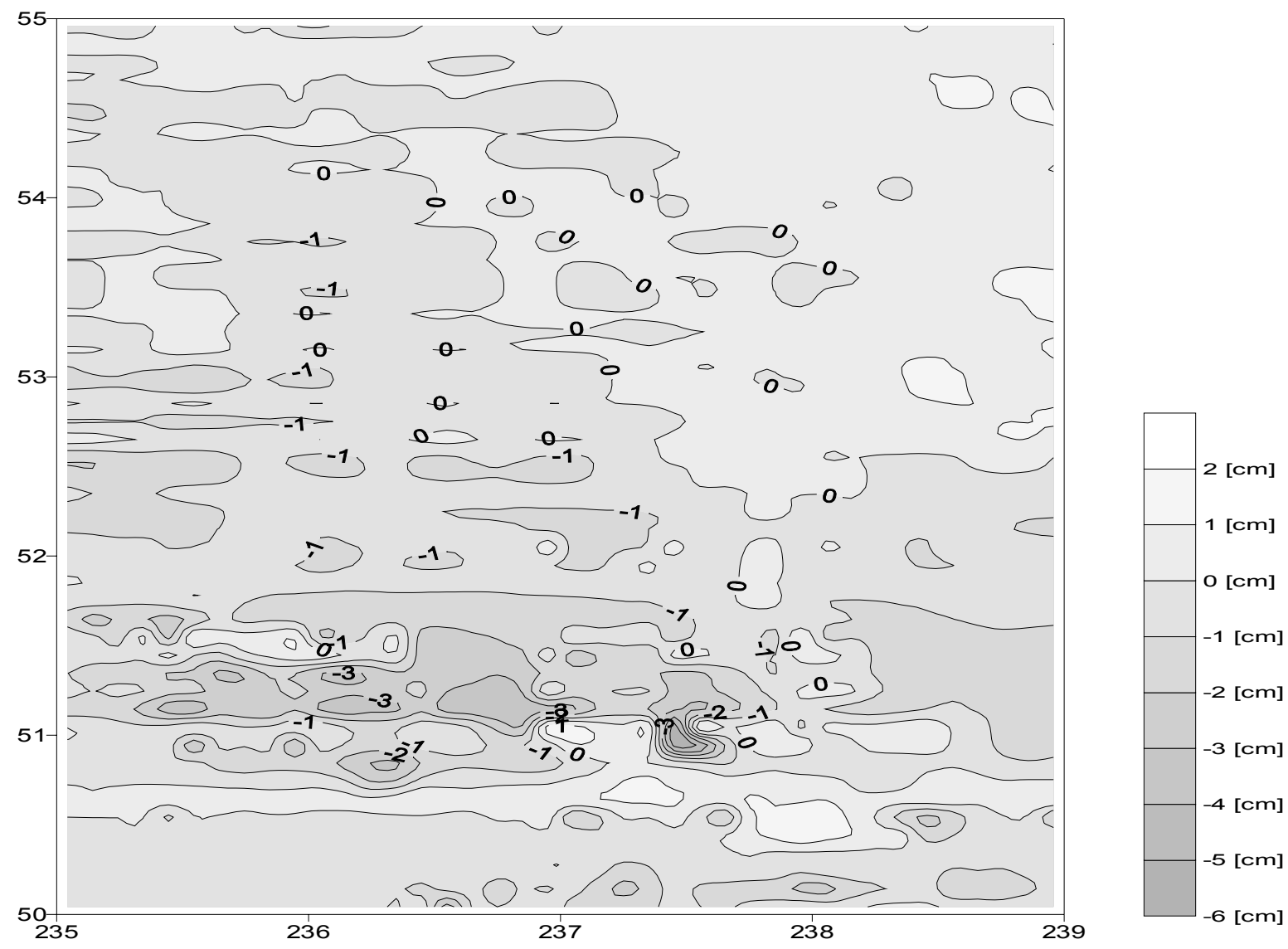

Fig. 4. Effect of anomalous topographical density distribution on the orthometric height (units in $\mathrm{cm}$ ) 


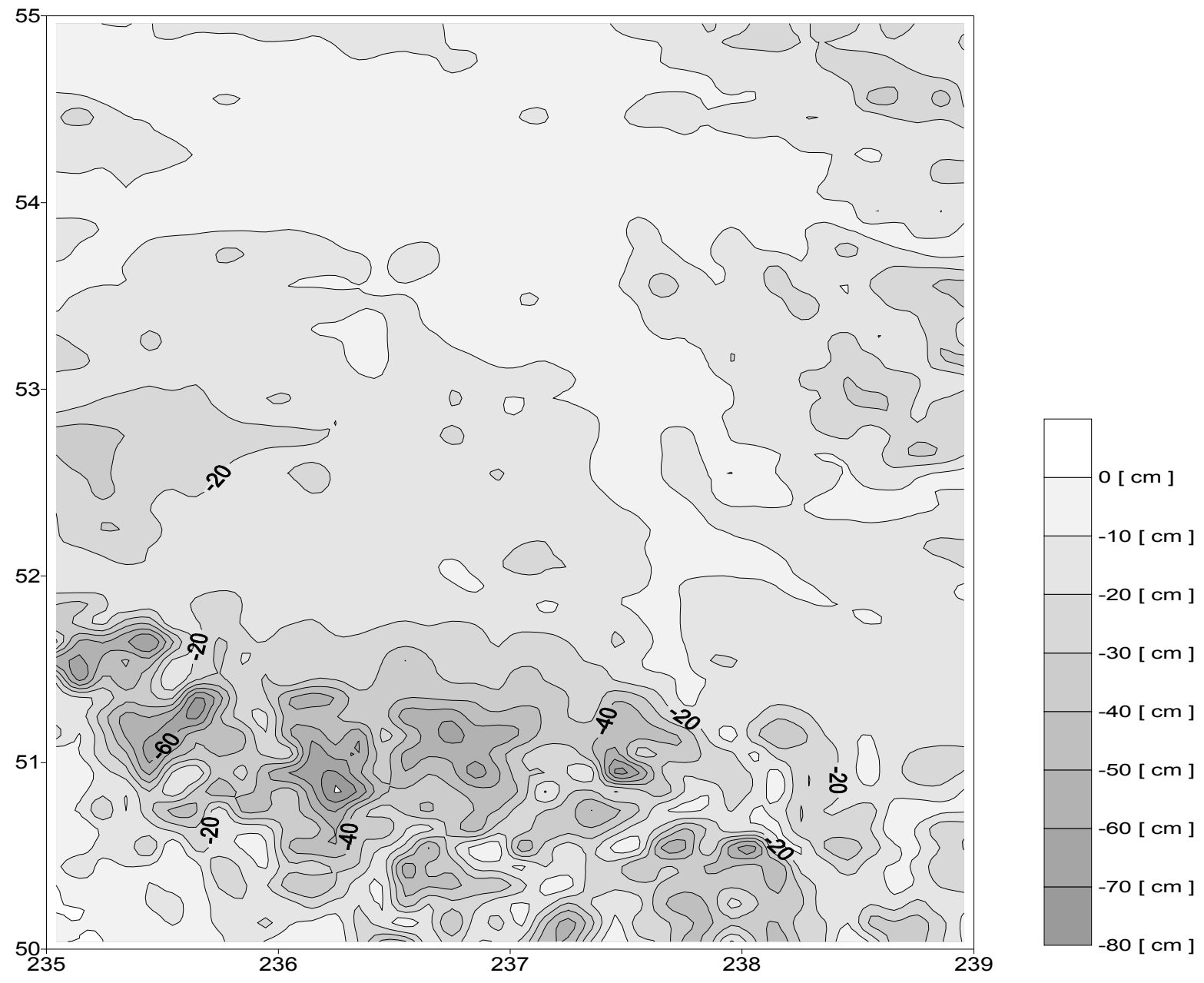

Figure 5. Combined effect of the topography (i.e., Bouguer shell, terrain roughness term, and anomalous topographic density) on the orthometric height (units in $\mathrm{cm}$ ) 


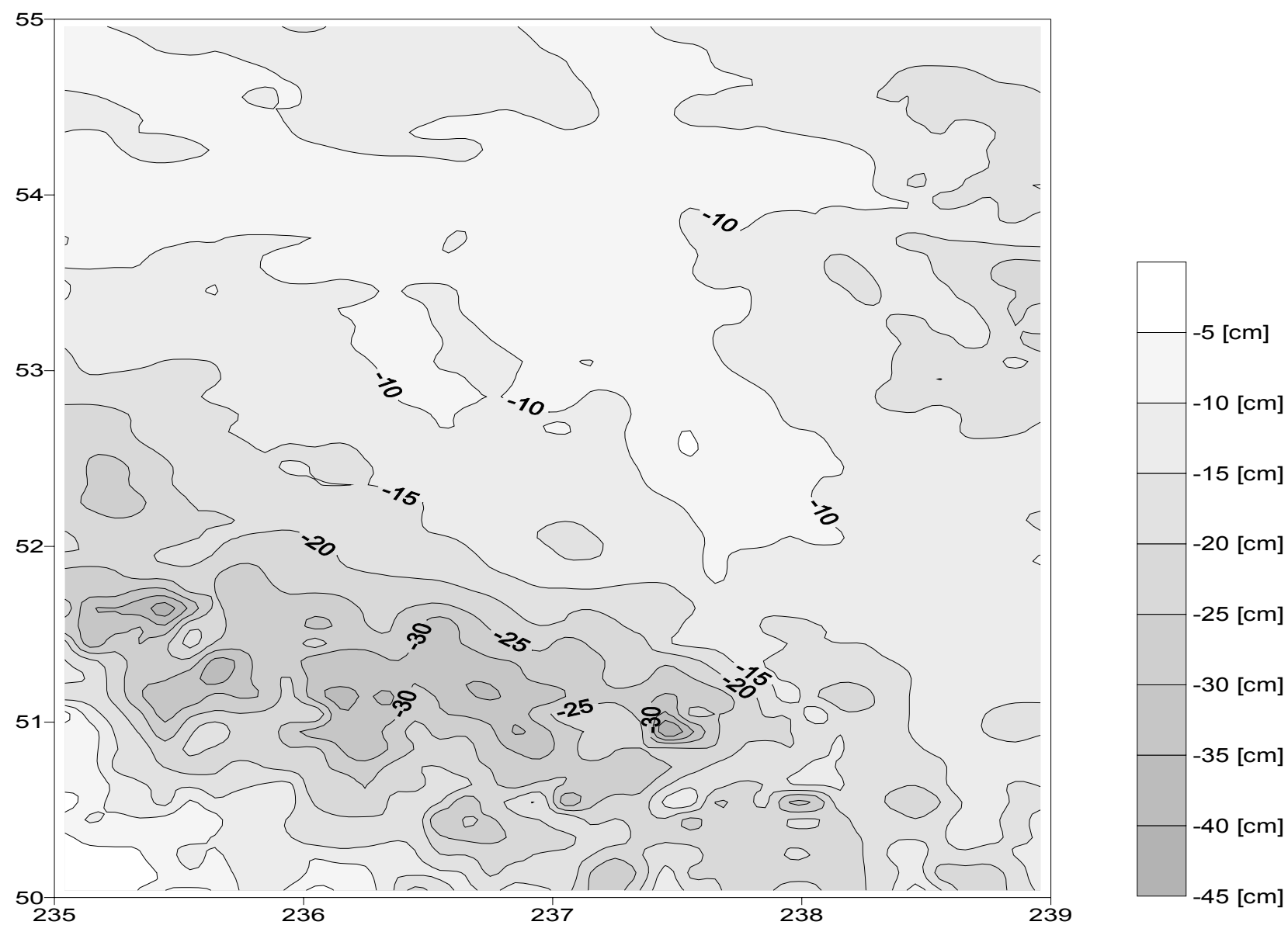

Figure 6. Differences between the rigorous orthometric height and normal height (units in $\mathrm{cm})$ 